Relato de caso / Case report

\title{
Envolvimento pulmonar na síndrome de Sweet paraneoplásica
}

\section{Pulmonary involvement in paraneoplastic Sweet's syndrome}

\author{
Marcelo Pavesi ${ }^{1}$ \\ Chiara S. Tessmer ${ }^{1}$ \\ Victor M. B. Garcia Neto ${ }^{1}$ \\ Jean Carlo Miller ${ }^{1}$ \\ Gilca Natchigal ${ }^{2}$ \\ Hiram L. Almeida Júnior ${ }^{3}$
}

\begin{abstract}
Síndrome de Sweet (dermatose neutrofílica febril aguda) é caracterizada por lesões cutâneas inflamatórias acompanhadas por febre, leucocitose e mal-estar, devendo ser reconhecida por hematologistas, já que freqüentemente é paraneoplásica. O envolvimento sistêmico pode estar presente e o comprometimento pulmonar, apesar de raro, tem sido reportado na forma de infiltração pulmonar bilateral, bronquiolite obliterante e derrame pleural. Há infiltração neutrofílica densa na histologia. Apresentamos o caso de uma paciente com leucemia mielóide crônica que desenvolveu a síndrome de Sweet com infiltrações pulmonares não infecciosas, as quais não foram responsivas à antibioticoterapia, porém mostraram melhora clínica com a corticoterapia. Rev. bras. hematol. hemoter. 2006; 28(4):307-309.
\end{abstract}

Palavras-chave: Síndrome de Sweet; acometimento pulmonar; dermatose neutrofílica febril aguda.

\section{Introdução}

Dermatose neutrofílica febril aguda foi pela primeira vez descrita em 1974 por Sweet. ${ }^{1}$ A etiologia dessa dermatose permanece desconhecida. Essa enfermidade foi inicialmente caracterizada como uma erupção aguda de placas e nódulos eritematosos, associados com febre, leucocitose e histologicamente apresentando infiltrado neutrofílico denso na derme. Subseqüentemente, outras lesões foram descritas, incluindo placas eritematosas, pápulas dolorosas com pústulas e bolhas. ${ }^{2}$ As lesões cutâneas envolvem mais comumente as extremidades superiores e a face. ${ }^{1}$

A síndrome tipicamente ocorre em mulheres de meia idade após uma infecção não específica do trato respiratório ou gastrointestinal, ou em associação a uma desordem hematopoiética, inflamatória ou neoplásica. ${ }^{3-6}$

A síndrome de Sweet já foi descrita envolvendo olhos, articulações, mucosa oral e órgãos como pulmão, fígado, rins e sistema nervoso central. ${ }^{3}$ Todavia, o acometimento pulmonar é raro, há apenas seis relatos descritos ${ }^{7-12}$ e nenhum des- tes estava associado à leucemia mielóide crônica (LMC). As manifestações pulmonares da síndrome descritas consistem em infiltrados bilaterais, bronquiolite obliterante com organização pneumônica e derrame pleural. Descreveremos um caso de dermatose neutrofílica aguda com envolvimento pulmonar em paciente com diagnóstico de LMC.

\section{Relato de Caso}

Paciente de 37 anos, feminina, branca, com diagnóstico há três meses de LMC é admitida para internação hospitalar apresentando febre com calafrios e tosse seca há três dias. Paciente é ex-tabagista. Não há dados relevantes de doenças pregressas. Ao exame físico a paciente apresentava-se febril (temperatura axilar $38^{\circ} \mathrm{C}$ ), taquicárdica ( $104 \mathrm{bpm}$ ), taquipneica (24 mrpm), com pressão arterial de 100/70mmHg, emagrecida (peso $36 \mathrm{~kg}$ ) e hipocorada. Havia esplenomegalia e linfonodos não inflamatórios palpáveis no cavo axilar direito. Também apresentava máculas eritematosas menores que $1 \mathrm{~cm}$ nos braços e nas pernas. Ausculta pulmonar e

\footnotetext{
${ }^{1}$ Acadêmico de Medicina.

${ }^{2}$ Hematologista.

${ }^{3}$ Professor adjunto de Dermatologia.

Correspondência: Hiram Larangeira de Almeida Jr.

Faculdade de Medicina da UFPEL

Av. Duque de Caxias 250

96.030-002 - Pelotas-RS - Brasil

E-mail: hiramalmeidajr@hotmail.com
}

Trabalho realizado no Hospital-Escola da Faculdade de Medicina da Universidade Federal de Pelotas. 
cardíaca sem alterações. Os exames da admissão eram: hematócrito 21.6\%, hemoglobina 7.0 g/dl, leucócitos 3700/ $\mathrm{mm}^{3}$ (bastões 3\%, segmentados $72 \%$, eosinófilos $2 \%$, basófilos $0 \%$, monócitos $2 \%$, linfócitos $21 \%$ ), contagem de plaquetas $610.000 / \mathrm{mm}^{3}$, creatinina $0.7 \mathrm{mg} / \mathrm{dl}$. Uma extensa investigação para encontrar um foco infeccioso foi realizada. A radiografia de tórax apresentava um infiltrado alveolar em "vidro fosco" em lobo inferior esquerdo. Bacterioscópio, e cultura para germes aeróbios e anaeróbios, pesquisa de BAAR, fungos do sangue, escarro, urina e das lesões cutâneas foram todos repetidamente negativos. Foram administrados antibióticos de amplo aspectro, antifúngico (anfotericina B) e antiviral (aciclovir) endovenosos, sem resposta.

Após seis dias, a paciente apresentou grande piora do quadro. Apresentava-se dispnéica, com edema de membros inferiores e superiores e persistentemente febril. As lesões de pele coalesceram, tornaram-se pustulosas e bolhosas e disseminaram-se (Figura 1). A radiografia de tórax apresentava infiltrado alveolar "em vidro fosco" em todo o pulmão esquerdo e derrame pleural ipsilateral com colapso parcial do lobo inferior (Figura 2). Foi realizada toracocentese e a análise do líquido pleural apresentava hemácias $2000 / \mathrm{mm}^{3}$, leucócitos 1800/ $\mathrm{mm}^{3}$ (70\% de polimorfonucleados), glicose $159 \mathrm{mg} / \mathrm{dl}$, proteínas totais $2.5 \mathrm{~g} / \mathrm{dl}$, DHL=172u/l; cultura, pes-

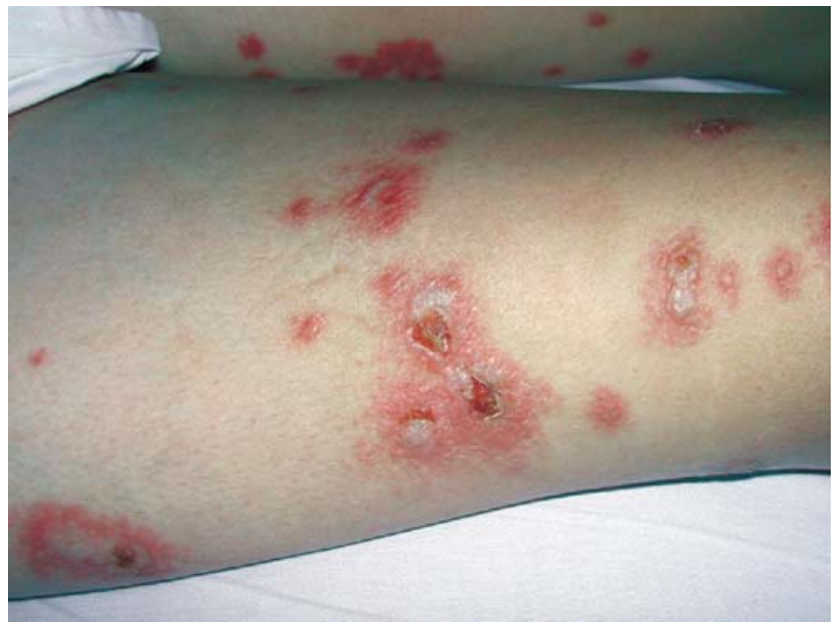

Figura 1. Placas eritematosas com pústulas na coxa direita

quisa de fungos e BAAR negativos.

Devido à piora do quadro, a paciente foi transferida para UTI. Foi colocada em ventilação mecânica e realizada reposição hídrica. Realizada novas culturas, as quais foram todas negativas; inclusive o bacterioscópio e a cultura do lavado broncoalveolar para fungos, BAAR,bactérias anaeróbias e aeróbias .

A avaliação dermatológica levou à hipótese de síndrome de Sweet, confirmada pela histologia cutânea, a qual mostrou densa infiltração neutrofílica da derme (Figura 3). Dessa

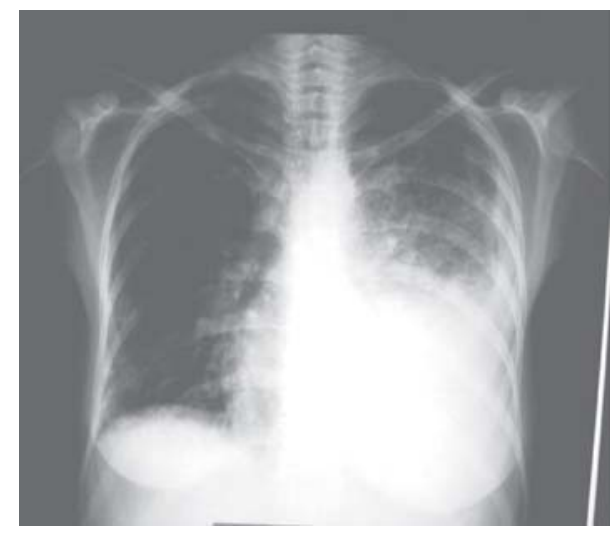

Figura 2.

Radiografia de tórax com infiltrado alveolar "em vidro fosco" em todo pulmão esquerdo e derrame pleural à ipsilateral com colapso parcial do lobo inferior

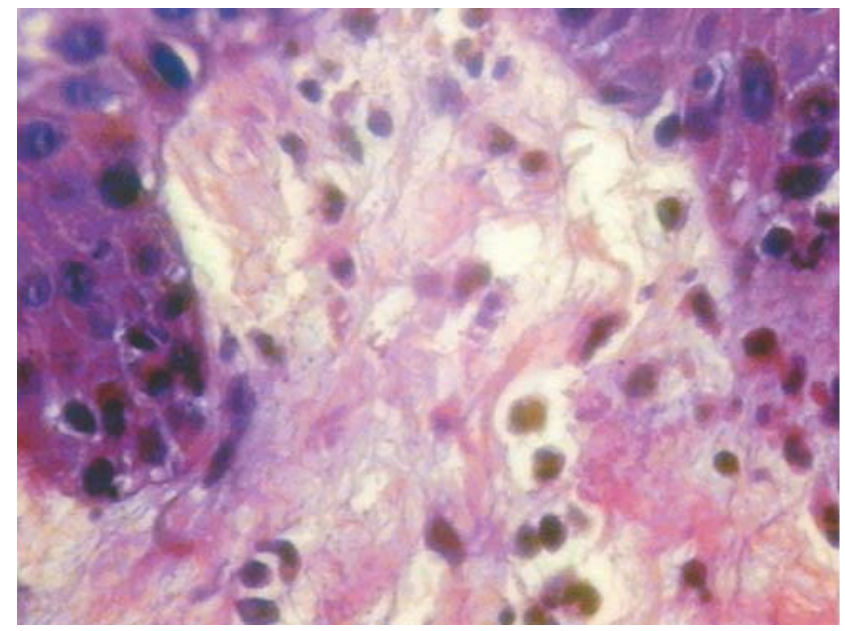

Figura 3. Densa infiltração neutrofílica e edema da derme papilar (hematoxila-eosina, aumento de 400 vezes)

forma, foi administrado hidrocortisona intravenosa. A paciente apresentou importante resposta ao tratamento, saindo da ventilação mecânica e apresentando-se hemodinamicamente estável. Após sete dias, teve súbita instabilidade hemodinâmica e critérios para Síndrome da Angústia Respiratória Sistêmica Aguda (SARA), evoluindo para o óbito, provavelmente por sepse.

\section{Discussão}

Por definição, a dermatose neutrofílica febril aguda (DNFA) tem os seguintes sinais cardinais: febre, leucocitose polimorfonuclear, placas dolorosas nas extremidades, face e pescoço e densa infiltração dérmica por neutrófilos maduros na histologia. ${ }^{1}$ Em 1986, Su e Liu ${ }^{13}$ propuseram dois critérios maiores e quatro critérios menores que servem como guia para o diagnóstico de DNFA. Para estabelecê-lo, deve-se preencher um critério maior e dois critérios menores. De acordo com essas diretrizes, o diagnóstico de DNFA pôde ser estabelecido. Como critério maior a paciente teve aparecimento abrupto de placa e nódulos cutâneos dolorosos com 
infiltração neutrofílica da derme demostrada pela histologia; já dentre os critérios menores, a paciente tinha uma neoplasia, apresentou febre antes da erupção das lesões cutâneas e obteve boa resposta à corticoterapia e não aos antibióticos .

O envolvimento pulmonar na DNFA foi pela primeira vez descrito em 1985 por Gibson et al ${ }^{7}$ numa série retrospectiva de 48 casos apresentados, ${ }^{16}$ nos quais cinco pacientes tiveram infiltrados pulmonares concomitantemente com a DNFA e todos apresentaram boa resposta a corticoesteróides e não à antibioticoterapia. No nosso caso, as lesões cutâneas foram confirmadas pela biópsia, e a piora dessas lesões foi acompanhada pela progressão do quadro pulmonar. A investigação para uma possível causa infecciosa foi repetidamente negativa. O predomínio de polimorfonucleares no exame do líquido pleural, os achados no lavado broncoalveolar sugestivos de alveolite neutrofílica e a pobre resposta ao uso de antibacterianos, antifúngico e antiviral sistêmicos levaram-nos ao diagnóstico de Síndrome de Sweet com comprometimento pulmonar.

Apesar de o comprometimento pulmonar na Síndrome de Sweet ser raro, sua identificação precoce leva a um diagnóstico preciso que possui um tratamento eficaz, possibilitando menor morbimortalidade.

\section{Abstract \\ Sweet's syndrome (acute febrile neutrophilic dermatosis) is characterized by inflammatory skin lesions accompanied by fever, leukocytosis and malaise, it should be recognized by hematologists, because it can be a paraneoplastic manifestation. Systemic involvement may be present and lung lesions, despite of the rarity, have been reported in the form of bilateral pulmonary infiltrations, bronchiolitis obliterans and pleural effusion. Histopathology shows dense neutrophilic infiltrates. We present a patient with chronic myeloid leukemia who developed Sweet's syndrome with bilateral pulmonary infiltrations, which were non-responsive to antibiotics but showed clinical improvement on steroid therapy. Rev. bras. hematol. hemoter. 2006; 28(4):307-309.}

Key words: Sweet's syndrome; pulmonary involvement; acute febrile neutrophilic dermatosis.

\section{Referências Bibliográficas}

1. Sweet RD.An acute febrile neutrophilic dermatosis. Br J Dermatol 1974;76:349-356.

2. Von den Driesch P. Sweet's syndrome (febrile neutrophilic dermatosis). J Am Acad Dematol 1994;31:535-556.

3. Cohen PR, Talpaz N, Kurzrock R. Malignanc-associated Sweet's syndrome: review of the world literature. J Clin Oncol 1988; 6:1.887-1.897.

4. Cooper PH, Innes DJ Jr, Greer KE. Acute febrile neutrophilic dermatosis (Sweet's syndrome) and myeloproliferative disorders. Cancer 1983;51:1.518-1.526.

5. Klock JC, Oken RL. Febrile neutrophilic dermatosis in acute myelogenous leukemia. Cancer 1976;37:922-927.
6. Spector JI, Zimbler H, Levine R, Ross JS, Valigorsky JM, Cole LM. Sweet syndrome-Association with acute leukemia. JAMA 1980; 4:283-288.

7. Gibson LE, Dicken CH, Flach DB. Neutrophilic dermatosis and mieloproliferative disease: report of two cases. Mayo Clin Proc 1985;60:735-40.

8. Lazarus AA, McMillan M, Miramadi A. Pulmonary involvement in Sweet's syndrome (acute febrile neutrophilic dermatosis). Chest 1986;90:922-4.

9. Takimoto CH, Warnock M, Golden JA. Sweet's syndrome with lung involvement. Am Rev Respir Dis 1991;143:177-9.

10. Bourke SJ, Quinn AG, Farr PM, Ashocroft T, Gibson GJ. Neutrophilic alveolitis in Sweet's syndrome. Thorax 1992; 47:572-573

11. Thurnheer R, Stammberger U, Hailemariam S, Russi EW. Bronchial manifestation of acute neutrophilic dermatosis (Sweet's syndrome). Eur Respir J 1998;11:976-980.

12. Ladhani S, Kamble RT, Sundaram P. Joshi JM. Non responding pneumonia with skin lesions. Indian J Chest Dis Allied Sci 2001; 43(2):115-7.

14. Su D, Liu H. Diagnosis criteria for Sweet's syndrome. Cutis 1986; 60:735-740.

15.Fett DL, Gibson LE, Su WPD. Sweet's syndrome: systemic signs and symptomes and associated disorders. Mayo Clin Proc 1995; $70: 234-240$

Avaliação: Editor e dois revisores externos

Conflito de interesse: não declarado

Recebido 14/02/2006

Aceito 18/04/2006 